\title{
Tenotomy or Tenodesis for Tendinopathy of the Long Head of the Biceps Brachii: An Updated Systematic Review and Meta-analysis
}

\author{
Bauke Kooistra, M.D., Ph.D., Navin Gurnani, M.D., Alexander Weening, M.D., \\ Derek van Deurzen, M.D., and Michel van den Bekerom, M.D., Ph.D.
}

\begin{abstract}
Purpose: The purpose of this meta-analysis was to provide an up-to-date comparison of clinical outcomes of tenotomy and tenodesis in the surgical treatment of long head of the biceps brachii (LHB) tendinopathy. Methods: A literature search was conducted in EMBASE, Pubmed/Medline and the Cochrane database from January 2000 to May 2020. All studies comparing clinical outcomes between LHB tenotomy and tenodesis were included. Quality was assessed using the Coleman score. Results: We included 25 studies (8 randomized studies) comprising 2,191 patients undergoing LHB tenotomy or tenodesis, with or without concomitant shoulder procedures (mainly rotator cuff repairs). The Coleman score ranged from 29 to 97 for all studies. When comparing tenodesis and tenotomy in randomized studies, no clinically relevant differences were found in the Constant score (mean difference, 0.9 points), the American Shoulder and Elbow Society Score (mean difference, 1.1 points), shoulder pain (mean difference in visual analogue scale, -0.3 points), elbow flexion strength loss (mean difference, $0 \%$ ), or forearm supination strength (mean difference, $3 \%$ ). A Popeye deformity (odds ratio, 0.32 ) was less commonly seen in patients treated with tenodesis ( $9 \%$ vs $23 \%$ ). Conclusion: In our metaanalysis, a Popeye deformity was more frequently observed in patients treated with tenotomy. Based on a substantial number of studies, there is no evidence-based benefit of LHB tenodesis over tenotomy in terms of shoulder function, shoulder pain or biceps-related strength. It is unclear whether LHB tenodesis is of benefit in specific patient groups such as younger individuals. Level of evidence: Level III, systematic review of level III or higher studies.
\end{abstract}

$\mathbf{T}$ endinopathy of the long head of the biceps brachii (LHB) is a highly prevalent pathology in patients with anterior and deep shoulder pain. ${ }^{1-3}$ Additionally, it is associated with rotator cuff tears and superior labrum anterior-to-posterior lesions, possibly because of load

From the Department of Orthopaedic Surgery, Medische Kliniek Velsen, Velsen-Noord, the Netherlands (B.K., N.G., A.W., D.v.D.); Department of Orthopaedic Surgery, Onze Lieve Vrouwe Gasthuis, Amsterdam, the Netherlands (B.K., M.v.d.B.); Department of Orthopaedic Surgery, Vrije Universiteit Medical Centre, Amsterdam, the Netherlands (M.v.d.B).

The authors report the following potential conflicts of interest: M. $v d B$ and D. $v$ D. have received research funding from Wright Medical and fellowship funding from Smith and Nephew. Full ICMJE author disclosure forms are available for this article online, as supplementary material.

Received September 11, 2020; accepted February 25, 2021.

Address correspondence to Bauke Kooistra, M.D., Ph.D., Onze Lieve Vrouwe Gasthuis, Oosterpark 9, 1090 HM Amsterdam, the Netherlands. E-mail:bwkooistra@gmail.com

(C) 2021 THE AUTHORS. Published by Elsevier Inc. on behalf of the Arthroscopy Association of North America. This is an open access article under the CC BY license (http://creativecommons.org/licenses/by/4.0/).

2666-061X/201500

https://doi.org/10.1016/j.asmr.2021.02.010 alterations within the LHB tendon due to muscletendon imbalance in the shoulder joint and because of the close anatomic relationship of these structures. ${ }^{4}$ The surgical treatment of LHB tendinopathy, whether or not associated with rotator cuff tears or rotator cuff tendinopathy, consists of arthroscopic debridement combined with either tenotomy or tenodesis of the LHB. Tenodesis has been favored by some because of potentially greater elbow flexion and forearm supination strength, less cramping pain and less risk of Popeye deformity.Yet disadvantages (longer surgical time, longer rehabilitation, higher costs, cramping pain, and persistent pain in the bicipital groove) have also been reported. ${ }^{2}$ However, a meta-analysis performed in 2015 that included 650 patients from 9 studies, of which only 1 was a randomized controlled trial (RCT), did not show clinically relevant differences in Constant Score, elbow flexion or forearm supination strength. After tenodesis, patients did have lower probabilities of Popeye deformity (odds ratio [OR] 0.17) and cramping pain (OR 0.38). ${ }^{5}$ Since then, several new comparative studies, including 7 RCTs, of LHB tenotomy and tenodesis have been published. 


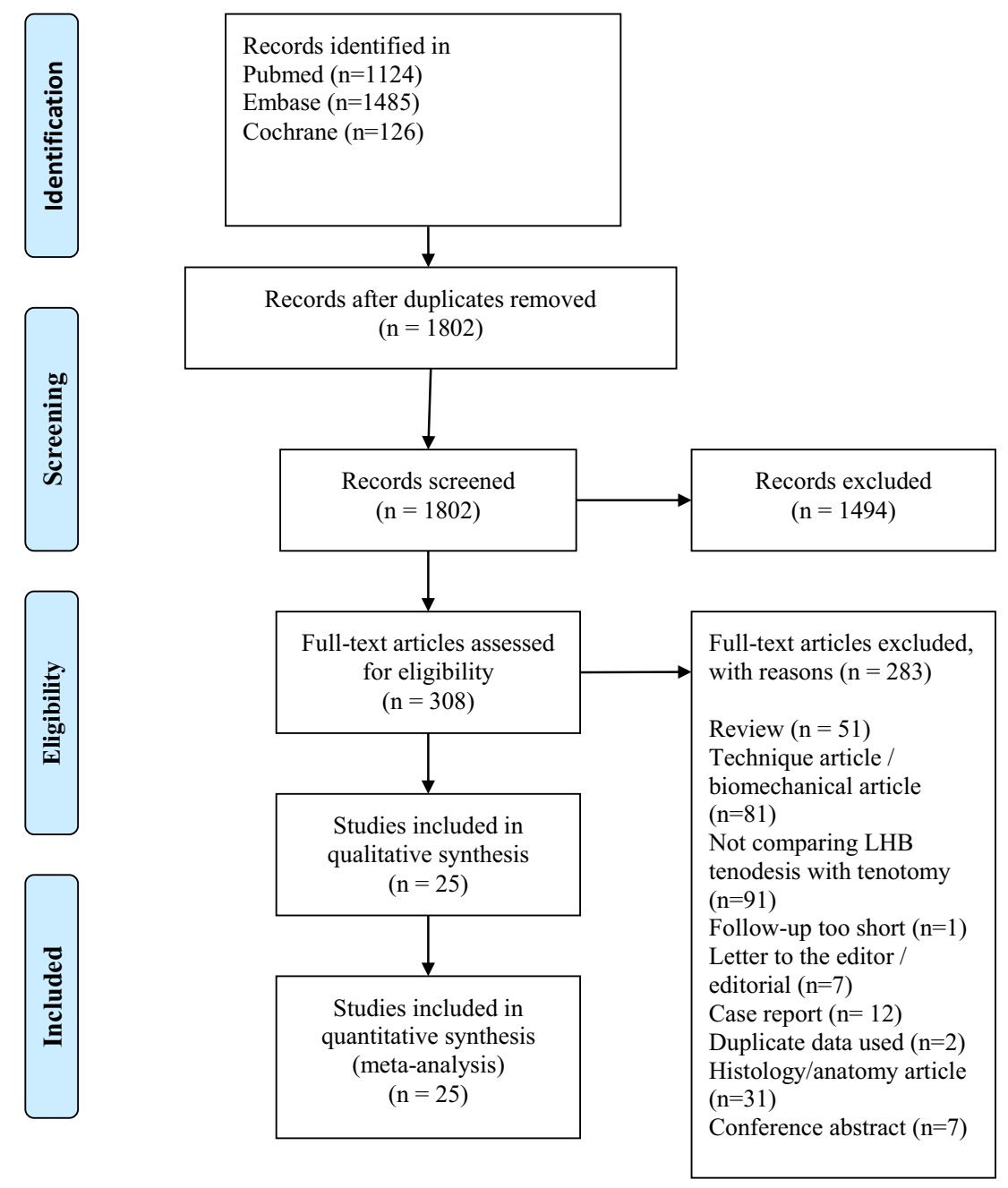

Fig 1. Flow diagram of study selection.

The purpose of this meta-analysis was to provide an up-to-date comparison of clinical outcomes of tenotomy and tenodesis in the surgical treatment of LHB tendinopathy. The primary hypothesis was that LHB tenotomy and tenodesis would show no difference in shoulder function, shoulder pain or biceps-related strength. Moreover, we hypothesized that after LHB tenodesis, patients would be less likely to experience cramping bicipital pain and Popeye deformities.

\section{Materials and Methods}

\section{Search Strategy}

Our original study protocol was a priori registered at the International Prospective Register of Systematic Reviews (PROSPERO) (http://www.crd.york.ac.uk/), number CRD42018087257. This systematic review was conducted according to the PRISMA guidelines. ${ }^{6}$ EMBASE, MEDLINE and Cochrane databases were searched for studies comparing LBH tenodesis with tenotomy, published from inception until May 24, 2020. The search strategy can be found in the
Appendix. Studies that described concomitant shoulder procedures, such as rotator cuff repair or labral repair, were included. Eligible studies had a minimum of 20 patients and a minimum follow-up of 12 months. The diagnosis of biceps tendinopathy had to be based on patient history, physical examination, ultrasound, MRI scan, or arthroscopic findings. Studies in languages other than English, Dutch or French were excluded (Fig 1). Two reviewers (NG and MB) searched the titles and abstracts for relevant studies. The full-text papers were examined by two authors (BWK and NG), and consensus was reached by discussion with the coauthors. Additionally, bibliographies of all obtained fulltext articles were hand-searched for potential additional relevant studies.

\section{Outcome Measures}

For conciseness, we chose to report only on outcomes that had been reported in a minimum of 3 studies. These were:

1. Constant score, with a minimal clinically important difference of 10 to 17 points $^{7-9}$ 
2. American Shoulder and Elbow Society Score $\mathrm{S}^{10}$

3. Elbow strength index (ESI), ${ }^{11}$ representing the ratio of the strength (measured in kilograms, Newtons, Newton-meters, or pounds) of elbow flexion on the affected side and the contralateral side during a single measurement

4. Forearm supination strength index (FSSI), ${ }^{11}$ representing the ratio of the strength (measured in kilograms, Newtons, Newton-meters, or pounds) of forearm supination on the affected side and the contralateral side during a single measurement, expressed in $\mathrm{Nm}$

5. Presence of a Popeye deformity

6. Presence of cramping pain in the biceps muscle

7. Shoulder pain, expressed as the Visual Analogue Scale (VAS), ranging from 0 to $10 .^{12}$

\section{Data Collection}

Two reviewers (BK and NG) extracted the data from the included papers. The investigations and their credentials were assessed by BK. Articles were not blinded for author, affiliation or source. If standard deviation was not mentioned, it was calculated based on the confidence interval. ${ }^{13}$

\section{Assessment of Risk of Bias}

The Coleman methodology score was used to determine the methodologic quality of included studies, with total scores ranging from 0 (worst score) to 100 (best score). The Coleman scoring system has been validated in various research facilities and is reproducible and accurate. ${ }^{14,15}$ The studies were scored by 3 reviewers (BK, NG and AW). Discrepancies were resolved by consensus.

\section{Statistical Analysis}

Study outcomes of RCTs were pooled when the outcome was reported by 3 or more studies. We used random effects models because we identified clinical heterogeneity among the included studies. ORs were reported for dichotomous outcomes, and mean differences (MDs) were reported for continuous outcomes measurements, along with corresponding 95\% confidence intervals (95\% CI) and 95\% prediction intervals (95\% PI). Forest plots were generated for each outcome index. Heterogeneity was assessed using the $\chi^{2}$ test.

We reported only outcomes of nonrandomized studies if certain outcome parameters were used in 3 or more studies. We did not pool outcomes of nonrandomized studies, but we reported the outcomes as ranges. Also, we created forest plots without pooled effect sizes, but we did calculate heterogeneity, expressed as the $\mathrm{I}^{2}$ statistic. We explored heterogeneity using subgroup analysis by minimum length of followup ( $<2$ years vs $\geq 2$ years), mean age $(<60$ years vs $\geq 60$ years), rate of concurrent cuff repairs $(<10 \%$ vs $\geq 10 \%$ of patients), rate of cointerventions, including cuff repair $(<10 \%$ vs $\geq 10 \%$ of patients), and type of tenodesis (subpectoral vs suprapectoral and intracuff). We chose the cut-off of $10 \%$ of concurrent cuff repairs and other cointerventions because we felt that such a low rate of cointerventions would not substantially influence the overall effect of the type of biceps treatment and because only very few studies would actually contain only patients without any cointerventions.

Statistical significance was defined as $P \leq 0.05$. To explore the effect of heterogeneity, sensitivity analyses were performed. Review Manager 5.2 (The Nordic Cochrane Centre, Copenhagen, Denmark; The Cochrane Collaboration) and R Project for Statistical Computing software (RStudio, version 1.2.1335; R Foundation for Statistical Computing, Vienna, Austria) were used for meta-analysis.

\section{Results}

\section{Included Studies}

The characteristics of the studies are summarized in Table 1. Twenty-five studies reporting on 2,191 participants were included in this meta-analysis. ${ }^{16-41}$ Of these, 1,003 patients were treated with tenodesis $(46 \%)$, and 1,188 were treated with tenotomy $(54 \%)$. There were 8 level I studies, 5 level II studies and 12 level III studies. The majority of the participants were treated for biceps pathology with concomitant rotator cuff lesions. Three studies included only patients with isolated LHB tendinopathy. In total, patients treated by tenodesis or tenotomy had similar rates of concomitant shoulder procedures. For all patients, follow-up ranged from 1 to 10 years.

\section{Quality Assessment}

The Coleman score ranged from 29 to 97 . The surgical procedure relating to the LHB tendon was described adequately (that is, in detail) in 14 studies; fairly (that is, mentioning only implants and approach) in 9 studies; and inadequately (that is, not mentioning anything) in 2. Fifteen studies reported the use of an independent outcome assessor. Six studies did not report patient recruitment adequately.

\section{Constant Score}

The Constant score was reported in 16 studies including 1,370 patients. In a meta-analysis of 5 RCTs (434 patients), the Constant score was similar for both groups (MD, 0.9 points) (95\% CI, - 1.5 to 3.4 points; $95 \%$ PI, -6.7 to 8.6 points) (Fig 2). This difference is smaller than the minimal clinically important differences.

For the nonrandomized studies, the mean difference in the Constant score ranged from -2.8 to 11.6 points in 


\begin{tabular}{|c|c|c|c|c|c|c|c|c|c|c|}
\hline Author & Study type, LoE & Coleman & $\mathrm{N}$ & Outcomes & $\begin{array}{l}\text { Included in } \\
\text { previous } \\
\text { review? }\end{array}$ & $\begin{array}{l}\text { Minimum } \\
\text { FU (yr) }\end{array}$ & Mean age & $\begin{array}{l}\text { Rate of patients } \\
\text { with concurrent } \\
\text { cuff repair }(\%)\end{array}$ & $\begin{array}{l}\text { Rate of patients } \\
\text { with } \\
\text { cointerventions (\%) }\end{array}$ & Tenodesis type \\
\hline Belay et al. & $\begin{array}{l}\text { Randomized } \\
\text { controlled triaI, I }\end{array}$ & 66 & 34 & VAS, ASES, SANE & No & 2 & 56 & 56 & 56 & Suprapectoral \\
\hline Castricini et al. & $\begin{array}{l}\text { Randomized } \\
\text { controlled trail, I }\end{array}$ & 91 & 55 & $\begin{array}{l}\text { Constant score, popeye deformity VAS, } \\
\text { SF } 36 \text {, ROM, elbow flexion strength, } \\
\text { cramping pain }\end{array}$ & No & 2 & 58 & 100 & 100 & Suprapectoral \\
\hline Hufeland et al. & $\begin{array}{l}\text { Randomized } \\
\text { controlled triaI, I }\end{array}$ & 78 & 20 & $\begin{array}{l}\text { Constant score, flexion strength, and } \\
\text { Popeye deformity }\end{array}$ & No & 1 & 52 & 0 & 0 & Suprapectoral \\
\hline Lee et al. & $\begin{array}{l}\text { Randomized } \\
\text { controlled trial, I }\end{array}$ & 94 & 128 & $\begin{array}{l}\text { ROM, VAS, ASES, Constant score, } \\
\text { Popeye deformity }\end{array}$ & No & 1 & 63 & 100 & 100 & Suprapectoral \\
\hline MacDonald et al. & $\begin{array}{l}\text { Randomized } \\
\text { controlled triaI, I }\end{array}$ & 78 & 114 & $\begin{array}{l}\text { ASES, WORC, VAS, elbow flexion and } \\
\text { supination strength (no comparison } \\
\text { with contralateral side), Popeye }\end{array}$ & No & 2 & 57 & 65 & 100 & Subpectoral \\
\hline Oh et al. & $\begin{array}{l}\text { Randomized } \\
\text { controlled trial, I }\end{array}$ & 86 & 86 & $\begin{array}{l}\text { ASES, VAS, flexion strength, supination } \\
\text { strength, Popeye deformity, cramping } \\
\text { pain and bicipital pain }\end{array}$ & No & 1 & 59 & 100 & 100 & Suprapectoral \\
\hline Van Deurzen et al. & $\begin{array}{l}\text { Randomized } \\
\text { controlled triaI, I }\end{array}$ & 78 & 100 & $\begin{array}{l}\text { Constant sore, ESI, DASH, DOSS, EQ5D, } \\
\text { VAS, external rotation, Popeye } \\
\text { deformity }\end{array}$ & No & 1 & 61 & 100 & 100 & Intracuff \\
\hline Zhang et al. & $\begin{array}{l}\text { Randomized } \\
\text { controlled trail, I }\end{array}$ & 97 & 151 & $\begin{array}{l}\text { Surgical time, cost, pain (VAS), Popeye } \\
\text { sign, flexion and supination strength } \\
\text { and Constant score }\end{array}$ & yes & 2 & 61 & 100 & 100 & Suprapectoral \\
\hline Aflatooni et al. & $\begin{array}{l}\text { Retrospective cohort } \\
\text { study, III }\end{array}$ & 66 & 215 & $\begin{array}{l}\text { Satisfaction, cramping pain, and bicipital } \\
\text { pain }\end{array}$ & No & 1.8 & 61 & 55 & 65 & Suprapectoral \\
\hline Biz et al. & $\begin{array}{l}\text { Prospective cohort } \\
\text { study, II }\end{array}$ & 33 & 252 & $\begin{array}{l}\text { Modified UCLA, VAS, SST, Popeye } \\
\text { deformity, bicipital and cramping pain }\end{array}$ & No & 1 & 57 & 100 & 100 & Intracuff \\
\hline Boileau et al. & $\begin{array}{l}\text { Retrospective cohort } \\
\text { study, III }\end{array}$ & 85 & 72 & $\begin{array}{l}\text { Constant score, ROM, biceps related } \\
\text { pain, radiologic changes, muscle } \\
\text { cramps, Popeye deformity }\end{array}$ & yes & 2 & 70 & 0 & 0 & Suprapectoral \\
\hline Cho et al. & $\begin{array}{l}\text { Retrospective cohort } \\
\text { study, III }\end{array}$ & 76 & 83 & $\begin{array}{l}\text { Constant score, UCLA score and Popeye } \\
\text { deformity, function, strength and } \\
\text { acromiohumeral distance }\end{array}$ & yes & 1.3 & 61 & 100 & 100 & Intracuff \\
\hline De Carli et al. & $\begin{array}{l}\text { Prospective cohort } \\
\text { study, II }\end{array}$ & 66 & 65 & $\begin{array}{l}\text { Strength, Constant score, Popeye } \\
\text { deformity }\end{array}$ & yes & 1.6 & 58 & 100 & 100 & Intracuff \\
\hline Delle Rose et al. & $\begin{array}{l}\text { Retrospective cohort } \\
\text { study, III }\end{array}$ & 71 & 104 & $\begin{array}{l}\text { Constant score, VAS and DASH and } \\
\text { cramping pain, Popeye deformity }\end{array}$ & yes & 2.4 & 48 & 0 & 0 & Intracuff \\
\hline Fang et al. & $\begin{array}{l}\text { Retrospective cohort } \\
\text { study, III }\end{array}$ & 58 & 154 & VAS, Constant score, ASES, DASH & No & 1 & 63 & 100 & 100 & Subpectoral \\
\hline Friedman et al. & $\begin{array}{l}\text { Retrospective cohort } \\
\text { study, III }\end{array}$ & 64 & 42 & $\begin{array}{l}\text { Popeye deformity, strength, ROM, VAS, } \\
\text { DASH, ASES, cramping pain, and } \\
\text { bicipital pain }\end{array}$ & No & 1.6 & 49 & 62 & 91 & Subpectoral \\
\hline Godenèche et al. & $\begin{array}{l}\text { Retrospective cohort } \\
\text { study, III }\end{array}$ & 71 & 134 & Constant score, SST and SSV & No & 10 & 56 & 100 & 100 & Suprapectoral \\
\hline Ikemoto et al. & $\begin{array}{l}\text { Retrospective cohort } \\
\text { study, III }\end{array}$ & 57 & 77 & $\begin{array}{l}\text { UCLA, ROM and elbow flexion strength, } \\
\text { Popeye deformity }\end{array}$ & No & 2 & 58 & 100 & 100 & Intracuff \\
\hline
\end{tabular}




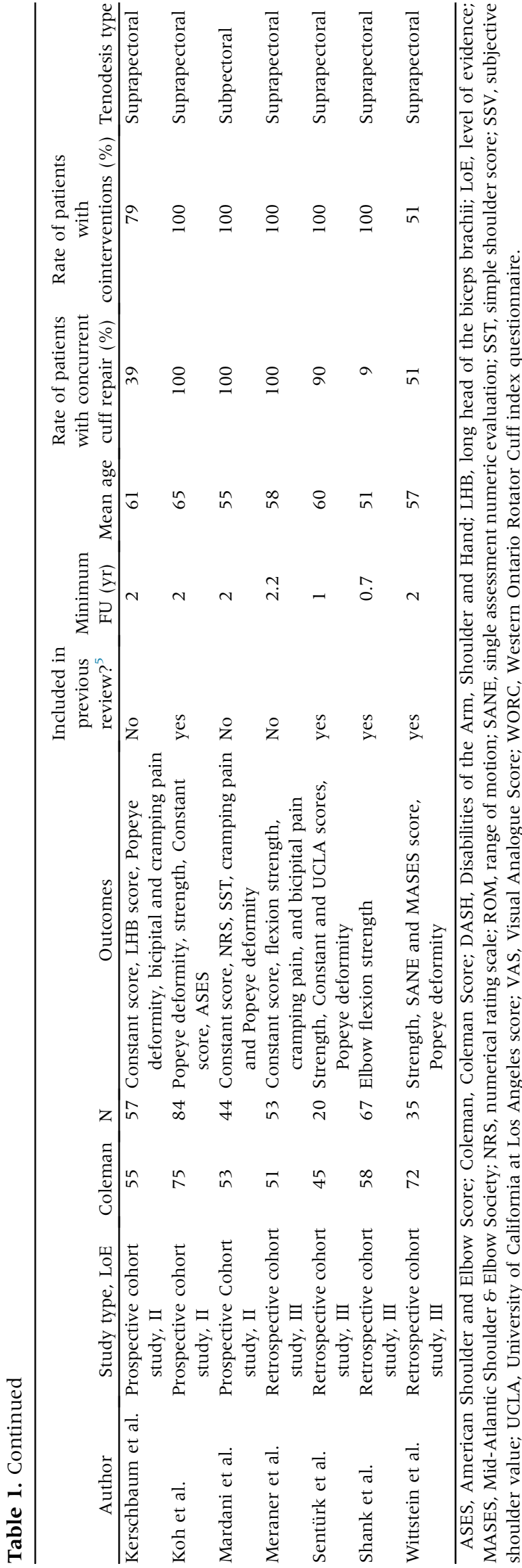

favor of tenodesis $\left(\mathrm{I}^{2}=64 \%\right)$. Subgroup analysis did not decrease heterogeneity.

\section{ASES Score}

The American Shoulder and Elbow Surgeons (ASES) score was reported in 4 studies including 360 patients. In a meta-analysis of 3 RCTs (206 patients), the ASES score was similar for both groups (MD, - 1.1 points; $95 \%$ CI, -5.8 to 3.6 points; $95 \%$ PI, -42.9 to 40.7 points) (Fig 3).

\section{Shoulder Pain}

Shoulder pain was reported in 5 studies including 454 patients. In a meta-analysis of 4 RCTs (300 patients), VAS for shoulder pain was similar for both groups (MD, -0.3 points $(95 \% \mathrm{CI},-1.0$ to 0.4 points; $95 \% \mathrm{PI},-2.3$ to 1.7 points) (Fig 4). This is not clinically significant.

\section{Popeye Deformity}

Popeye deformity was reported in 22 studies including 1,370 patients. In a meta-analysis of 7 RCTs (627 patients), Popeye deformity occurred more commonly in patients after tenotomy (OR, 0.32 points (95\% CI, 0.18-0.57 points; 95\% PI, 0.10-1.08) (Fig 5). In the population included in our meta-analysis, $23 \%$ of patients developed a Popeye deformity after tenotomy as compared to $9 \%$ after tenodesis. For the nonrandomized studies, the OR ranged from 0.02 to 1.49 $\left(\mathrm{I}^{2}=48 \%\right)$. Including only studies with at least 2 years of follow-up decreased heterogeneity substantially $\left(\mathrm{I}^{2}=\right.$ $2 \%)$.

\section{ESI}

ESI was reported in 8 studies including 535 patients (Fig 6). In a meta-analysis of 4 RCTs (315 patients), the ESI was similar in both groups (MD, 0 loss of strength compared to the contralateral side, $95 \%$ CI, $-5 \%$ to $6 \%$; $96 \%$ PI, $-12 \%$ to $12 \%)$.

\section{FSSI}

FSSI was reported in 5 studies including 300 patients (Fig 7). In a meta-analysis of 3 RCTs (329 patients), the FFSI was similar in both groups (MD, 3\% loss of strength compared to the contralateral side in favor of tenodesis $(95 \% \mathrm{CI},-10 \%$ to $16 \%$; $96 \% \mathrm{PI},-123 \%$ to $129 \%)$.

\section{Cramping Bicipital Pain}

Cramping pain in the biceps muscle was reported in 10 studies including 888 patients (Fig 8). These studies included 2 RCTs. In a meta-analysis of 2 RCTs (209 patients), there was no difference between the groups regarding cramping pain (OR, 0.58; 95\% CI, 0.201.69)). In the nonrandomized studies, the OR for the presence of cramping pain ranged from 0.03 to 2.74 $\left(\mathrm{I}^{2}=32 \%\right)$. Including only studies of patients with a mean age older than 60 years decreased heterogeneity 


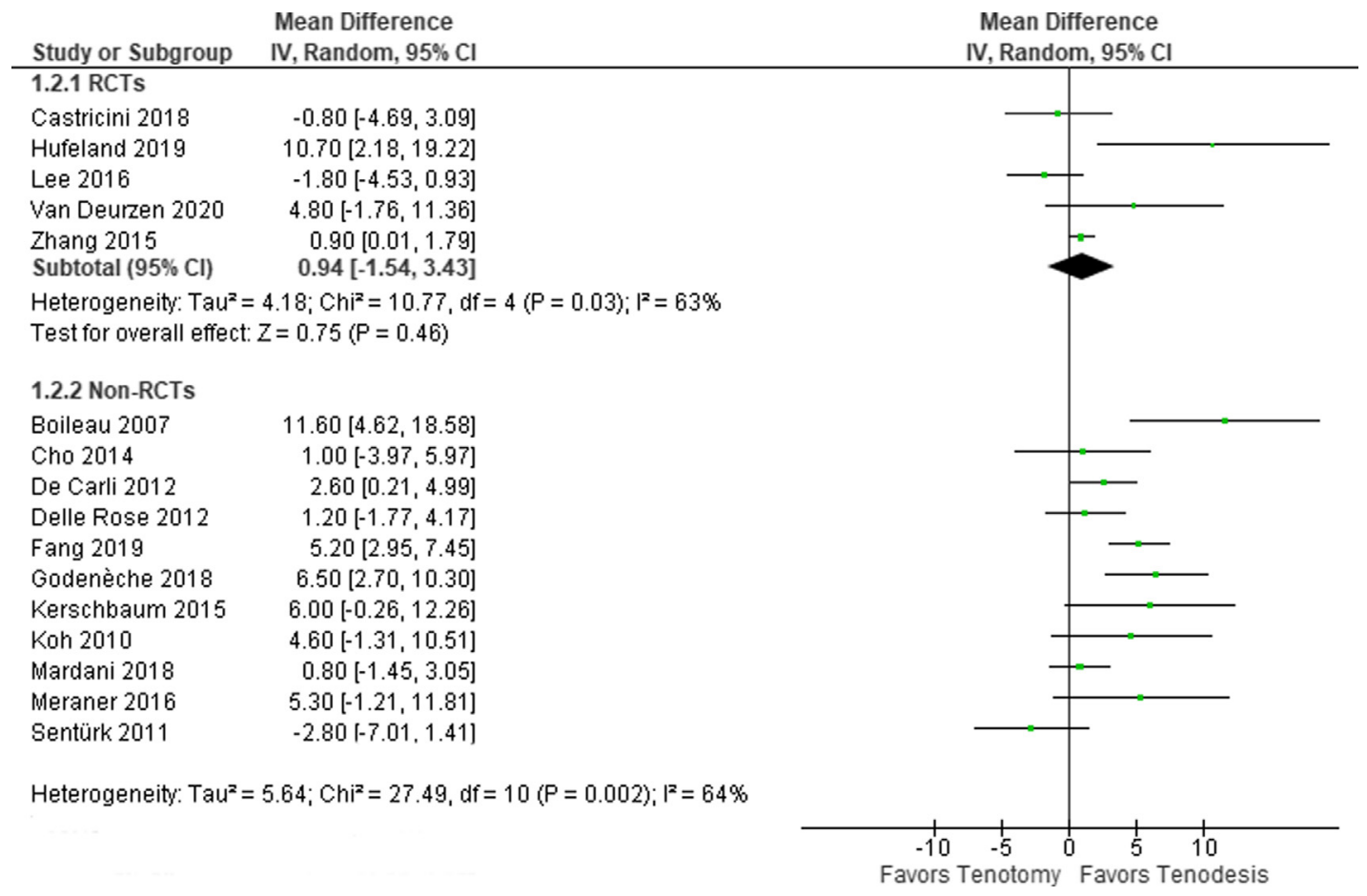

Fig 2. Forest plot of the Constant score.

substantially $\left(\mathrm{I}^{2}=0 \%\right)$. Similarly, including only studies with $<10 \%$ of concurrent cuff repairs and $<10 \%$ of cointerventions decreased heterogeneity substantially $\left(\mathrm{I}^{2}=2 \%\right)$.

\section{Discussion}

The present meta-analysis did not demonstrate a clinically significant advantage of LHB tenodesis over tenotomy in terms of shoulder function, shoulder pain or biceps-related strength. Popeye deformity and cramping pain were more commonly observed in patients after tenotomy. Overall, the nature of the findings is similar to that of previous meta-analyses that also included nonrandomized studies in the pooling of data. ${ }^{5,42,43}$ However, the evidence base of our findings is much greater because we included only RCTs in the meta-analysis. Compared to the previous review, ${ }^{5}$ there were 16 new studies and 1,541 new patients; these included 7 new RCTs ${ }^{15,20,26,30,33,39,40}$ with a total of 511 new patients.
When strictly adhering to these findings, the only reason to perform an LHB tenodesis would be to reduce the likelihood of having a Popeye deformity or cramping bicipital pain. Indeed, a majority of patients preferred LHB tenodesis over tenotomy in a recent study, irrespective of their ages. ${ }^{44}$ The main reason for this preference was concern about upper-arm appearance. Yet in another recent study of 41 patients after LHB suprapectoral tenotomy (mean age 58 years, range 27-76), none of the 15 patients who developed a Popeye deformity had cosmetic complaints. ${ }^{45}$ In the same study, 26 patients developed autotenodesis of the LHB tendon stump in the intertubercular groove, as confirmed by ultrasound. ${ }^{45}$ These data may be used for counseling so patients are not concerned about the occurrence of a Popeye deformity. ${ }^{46}$ In our analysis, all LHB tenodesis techniques were analyzed together, and we did not find any clinically significant differences (that is, a difference equal to or larger than the minimal clinically important differences compared to LHB

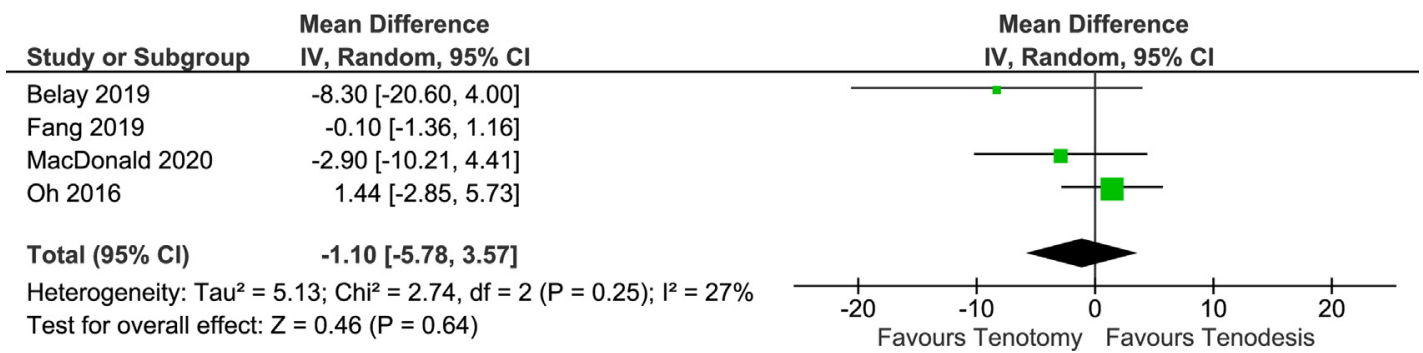

Fig 3. Forest plot of the American Shoulder \& Elbow Surgeons score. 


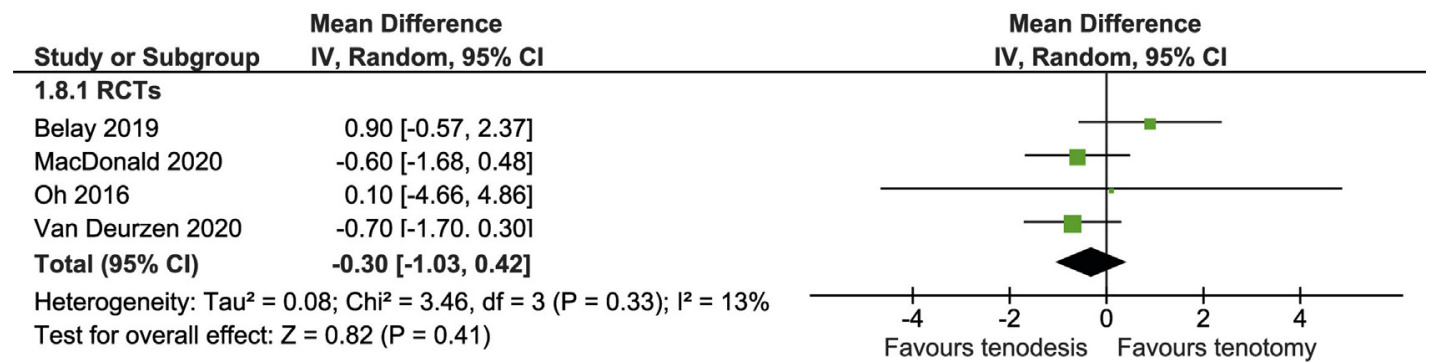

Fig 4. Forest plot of shoulder pain (Visual Analogue Scale).

tenotomy. Yet a recent network meta-analysis by Anil and colleagues separately compared all tenodesis techniques (arthroscopic intracuff tenodesis, arthroscopic suprapectoral tenodesis and open subpectoral tenodesis) with tenotomy across 22 studies. ${ }^{47}$ It was concluded that all tenodesis techniques yield superior functional outcomes to those of tenotomy. The clinical significance of the observed differences $(<5$ for ASES,
$<4$ for the Constant score), however, can be questioned, and our conclusion would be more conservative (i.e., that there is no clinical difference between tenodesis and tenotomy). Importantly, Anil and colleagues did find a clearly higher rate of persistent bicipital groove pain after intra-cuff tenodesis compared to tenotomy (OR, 2.9), which can be a sound argument to refrain from this tenodesis technique. Suprapectoral

Odds Ratio

Odds Ratio

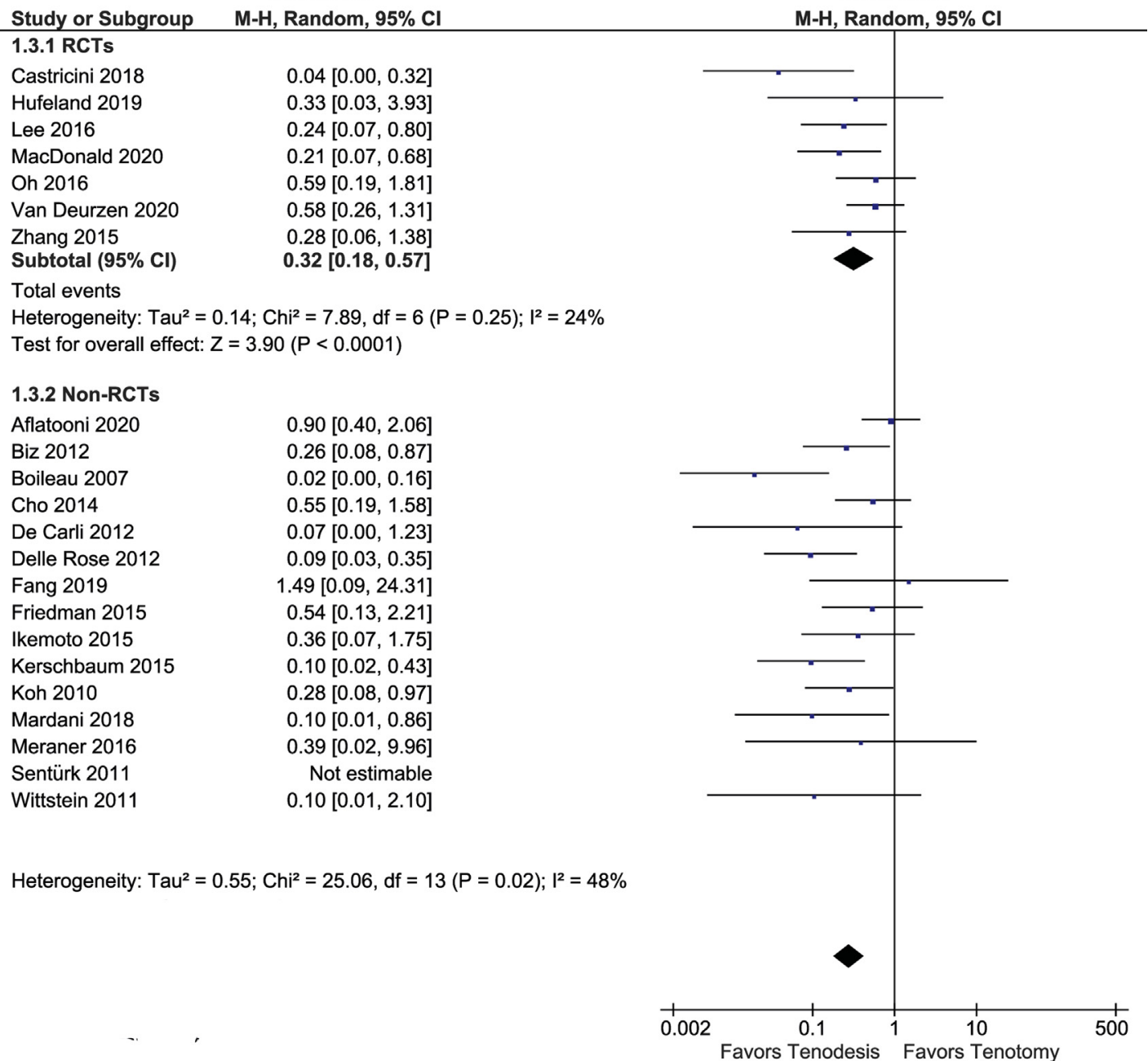

Fig 5. Forest plot of the presence of a Popeye deformity. 


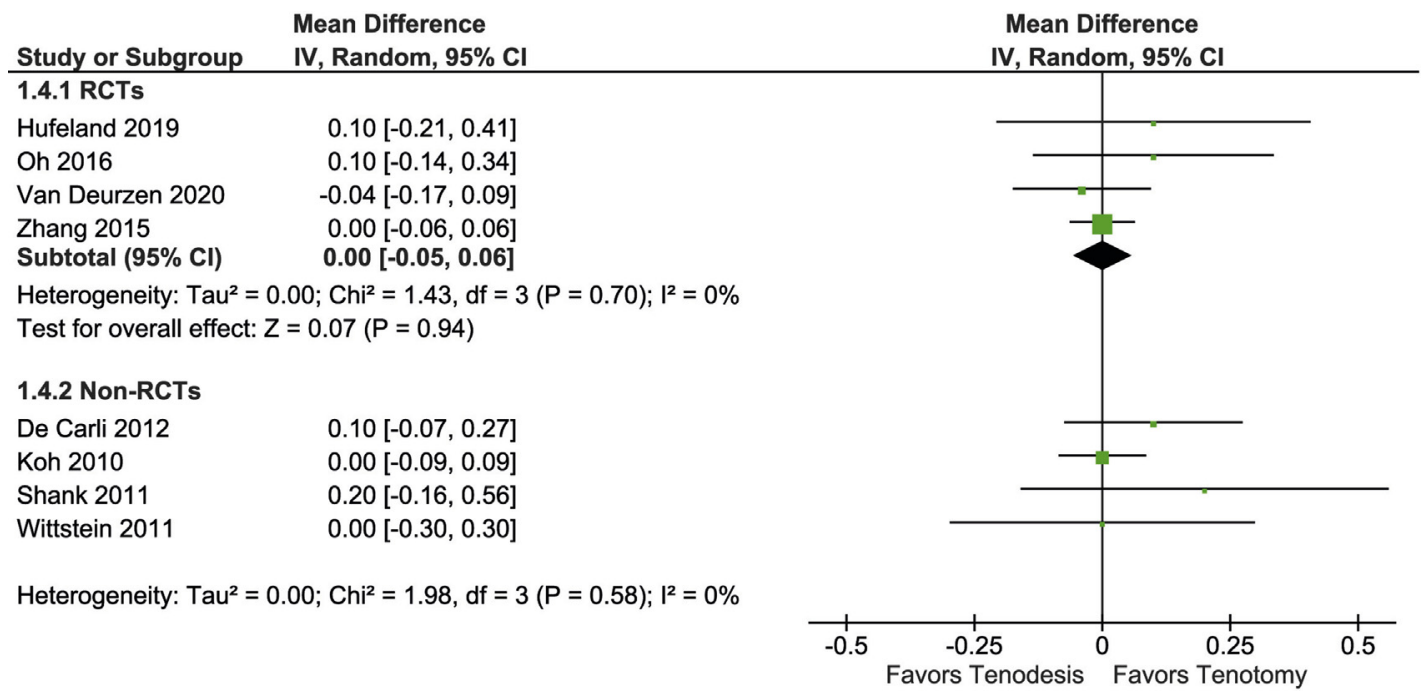

Fig 6. Forest plot of elbow flexion strength.

and subpectoral tenodeses had similar clinical improvements as was also confirmed by a recent focused comparative meta-analysis. ${ }^{48}$

It is of special interest in the present review that including or excluding lower-quality studies (that is, level 2 and 3 studies) did not change the results of the meta-analysis. Therefore, the usefulness of nonrandomized studies should not be underestimated.

Future randomized controlled trials concerning LHB tenotomy and tenodesis may stratify for patient age, may exclude patients with cointerventions and should incorporate patient-reported outcomes, including patient satisfaction. In this light, registry-based studies may offer sensible study designs to evaluate subgroups that may benefit from LHB tenodesis. Furthermore, based on our exploration of heterogeneity, future studies should include a more homogeneous age category (for example, only patients older than 60 years of age or only patients younger than 40 years of age) and should have a follow-up of at least 2 years.

\section{Limitations}

Our meta-analysis has several limitations. First, the quality of the included studies is highly variable, as is evident from the wide range in Coleman scores. This limits the quality of the summary estimates of the meta-analysis. However, the results were not changed when analyzing only RCTs.

A second limitation is the high frequency of cointerventions in the included studies, mainly rotator cuff repair. Only 3 of 25 studies reported solely on patients with no concomitant procedures. Therefore, improvements in outcome parameters may be attributed to these cointerventions, so the isolated effect of LHB treatment can become hard to measure. Indeed, our subgroup analysis of studies with less than $10 \%$ of cointerventions resulted in very low heterogeneity for studies on bicipital pain.

Third, the outcome measures used in the studies may be insufficient. ${ }^{49}$ The Constant score may have a ceiling effect for LHB-related complaints in patients after rotator cuff repair ${ }^{50}$ because LHB tendinopathy causes mainly pain, not functional impairment. Elbow flexion and forearm supination strength were recorded only during a single measurement, not taking into account potential muscle fatigue. The LHB tendon may account for only $8 \%-20 \%$ of forearm supination strength, ${ }^{20}$ so these measurements may be insufficient to detect smaller differences that may be clinically important, mainly in younger patients. Using the LHB score may

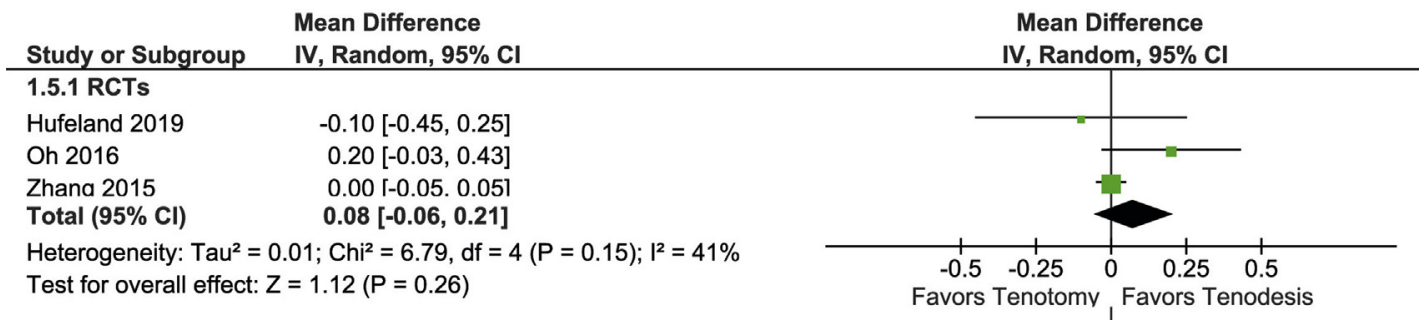

Fig 7. Forest plot of supination strength. 


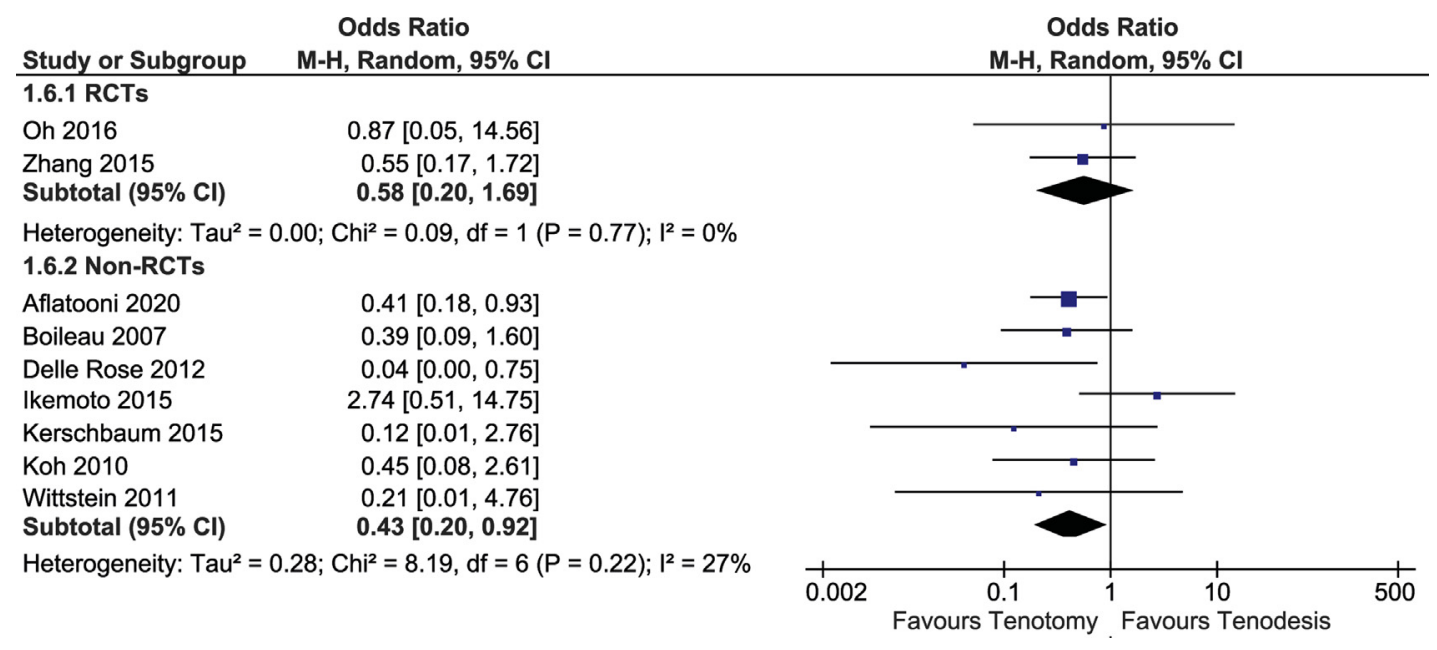

Fig 8. Forest plot of the presence of cramping pain.

provide more specific information regarding LHBrelated complaints. ${ }^{51}$ Ultimately, studies lack patient satisfaction measurements, which may be relatively important in a population where preoperative cosmetic concerns are prevalent. ${ }^{44}$

Fourth, no distinction is made regarding patient age or activity level. For example, younger and more active patients may benefit more from a tenodesis in terms of elbow flexion and/or forearm supination strength. One should be cautious about applying the present findings to all individuals.

The last limitation of the meta-analysis is that the location of the tenodesis is not analyzed separately. For example, it can be hypothesized that subpectoral tenodesis removes the LHB tendon entirely from the intertubercular groove, whereas higher tenodeses and the majority of tenotomies leave the tendon trapped in the groove. Some authors suggested that the surrounding tissues in the bicipital grove such as the transverse ligament may play a role in persisting pain after either LHB tenotomy or tenodesis. ${ }^{52,53}$ Persisting pain after either procedure may be explained in cases in which deroofing the bicipital groove has not been performed, ${ }^{52}$ which could clarify the similar results with regard to persisting pain in both groups in this meta-analysis. Surprisingly, Anil and colleagues found the lowest rates of persistent groove pain in groups that had undergone arthroscopic suprapectoral tenodesis, ${ }^{47}$ and a recent meta-analysis by van Deurzen and colleagues found no clinically relevant differences between suprapectoral and subpectoral tenodesis.

\section{Conclusions}

In our meta-analysis, a Popeye deformity was more commonly observed in patients treated with tenotomy. Based on findings in a substantial number of studies, there is no evidence-based benefit of LHB tenodesis over tenotomy in terms of shoulder function, shoulder pain or biceps-related strength. It is unclear whether LHB tenodesis is of benefit in specific patient groups such as younger individuals.

\section{References}

1. Ahrens PM, Boileau P. The long head of biceps and associated tendinopathy. J Bone Joint Surg Br 2007;89: 1001-1009.

2. Longo UG, Loppini M, Marineo G, et al. Tendinopathy of the tendon of the long head of the biceps. Sports Med Arthrosc Rev 2011;19:321-324.

3. Meeks BD, Meeks NM, Froehle AW, Wareing E, Bonner KF. Patient satisfaction after biceps tenotomy. Orthop J Sports Med 2017;5:2325967117707737.

4. Sakurai G, Ozaki J, Tomita Y, et al. Morphologic changes in long head of biceps brachii in rotator cuff dysfunction. J Orthop Sci 1998;3:137-142.

5. Gurnani N, van Deurzen DFP, Janmaat VT, van den Bekerom MPJ. Tenotomy or tenodesis for pathology of the long head of the biceps brachii: A systematic review and meta-analysis. Knee Surg Sport Traumatol Arthrosc 2016;24:3765-3771.

6. Knobloch K, Yoon U, Vogt PM. Preferred reporting items for systematic reviews and meta-analyses (PRISMA) statement and publication bias. J Craniomaxillofac Surg 2011;39:91-92.

7. Roy JS, MacDermid JC, Woodhouse LJ. A systematic review of the psychometric properties of the ConstantMurley score. J Shoulder Elbow Surg 2010;19:157-164.

8. Holmgren T, Öberg B, Adolfsson L, Björnsson Hallgren H, Johansson K. Minimal important changes in the Constant-Murley score in patients with subacromial pain. J Shoulder Elbow Surg 2014;23:1083-1090. doi:10.1016/j. jse.2014.01.014.

9. Kukkonen J, Kauko T, Vahlberg T, Joukainen A, Äärimaa V. Investigating minimal clinically important difference for Constant score in patients undergoing rotator cuff surgery. J Shoulder Elbow Surg 2013;22: 1650-1655. 
10. Michener LA, McClure PW, Sennett BJ. American Shoulder and Elbow Surgeons Standardized Shoulder Assessment Form, patient self-report section: Reliability, validity, and responsiveness. J Shoulder Elbow Surg 2002;11:587-594.

11. Kerschbaum M, Maziak N, Bohm E, Scheibel M. Elbow flexion and forearm supination strength in a healthy population. J Shoulder Elbow Surg 2007;26: 1616-1619.

12. Dauphin AP, Guillemin F, Virion JM, Briancon S. Bias and precision in visual analogue scales: A randomized controlled trial. Am J Epidemiol 1999;150:1117-1127.

13. Walter SD, Yao X. Effect sizes can be calculated for studies reporting ranges for outcome variables in systematic reviews. J Clin Epidemiol 2007;60:849-852.

14. Coleman BD, Khan KM, Maffulli N, Cook JL, Wark JD. Studies of surgical outcome after patellar tendinopathy: Clinical significance of methodological deficiencies and guidelines for future studies. Victorian Institute of Sport Tendon Study Group. Scand J Med Sci Sports 2000;10:2-11.

15. Frost A, Zafar MS, Maffulli N. Tenotomy versus tenodesis in the management of pathologic lesions of the tendon of the long head of the biceps brachii. Am J Sports Med 2009;37:828-833.

16. Belay ES, Wittstein JR, Garrigues GE, et al. Biceps tenotomy has earlier pain relief compared to biceps tenodesis: A randomized prospective study. Knee Surg Sports Traumatol Arthrosc 2019;27:4032-4037.

17. Biz C, Vinanti GB, Rossato A, Arnaldi E, Aldegheri R. Prospective study of three surgical procedures for long head biceps tendinopathy associated with rotator cuff tears. Muscles Ligaments Tendons J 2012;2:133-136.

18. Boileau P, Baqué F, Valerio L, Ahrens P, Chuinard C, Trojani C. Isolated arthroscopic biceps tenotomy or tenodesis improves symptoms in patients with massive irreparable rotator cuff tears. J Bone Jt Surg 2007;89: 747-757.

19. De Carli A, Vadalà A, Zanzotto E, et al. Reparable rotator cuff tears with concomitant long-head biceps lesions: Tenotomy or tenotomy/tenodesis? Knee Surg Sports Traumatol Arthrosc 2012;20:2553-2558.

20. Carpenter JE, Flanagan CL, Thomopoulos S, Yian EH, Soslowsky LJ. The effects of overuse combined with intrinsic or extrinsic alterations in an animal model of rotator cuff tendinosis. Am J Sports Med 1998;26:801-807.

21. Castricini R, Familiari F, De Gori M, et al. Tenodesis is not superior to tenotomy in the treatment of the long head of biceps tendon lesions. Knee Surg Sports Traumatol Arthrosc 2018;26:169-175.

22. Cho NS, Cha SW, Rhee YG. Funnel tenotomy versus intracuff tenodesis for lesions of the long head of the biceps tendon associated with rotator cuff tears. Am J Sports Med 2014;42:1161-1168.

23. Delle Rose G, Borroni M, Silvestro A, et al. The long head of biceps as a source of pain in active population: Tenotomy or tenodesis? A comparison of 2 case series with isolated lesions. Musculoskelet Surg 2012;96:S47-S52 (Suppl 1).

24. Fang JH, Dai XS, Yu XN, et al. Lesions of the long head of the biceps tendon concomitant with rotator cuff tears: Tenotomy or subpectoral mini-open tenodesis? A comparative short to mid-term follow-up study. Orthop Surg 2019;1 1:857-863.

25. Friedman JL, FitzPatrick JL, Rylander LS, Bennett C, Vidal AF, McCarty EC. Biceps tenotomy versus tenodesis in active patients younger than 55 years: Is there a difference in strength and outcomes? Orthop J Sports Med 2015;3:2325967115570848.

26. Godenèche A, Kempf JF, Nové-Josserand L, Michelet A, Saffarini M, Hannink G. Tenodesis renders better results than tenotomy in repairs of isolated supraspinatus tears with pathologic biceps. J Shoulder Elbow Surg 2018;27: 1939- 1945.

27. Hufeland M, Wicke S, Verde PE, Krauspe R, Patzer T. Biceps tenodesis versus tenotomy in isolated LHB lesions: A prospective randomized clinical trial. Arch Orthop Trauma Surg 2019;139:961-970.

28. Ikemoto RY, PbelayE Pileggi, Murachovsky J, Nascimento JGP, Serpone RB, Strose E. Tenotomy with or without tenodesis of the long head of the biceps using repair of the rotator cuff. Rev Bras Ortop 2012;476: 736-740.

29. Kerschbaum M, Arndt L, Bartsch M, Chen J, Gerhardt C, Scheibel M. Using the LHB score for assessment of LHB pathologies and LHB surgery: A prospective study. Arch Orthop Trauma Surg 2016;136:469-475.

30. Koh KH, Ahn JH, Kim SM, Yoo JC. Treatment of biceps tendon lesions in the setting of rotator cuff tears: Prospective cohort study of tenotomy versus tenodesis. Am J Sports Med 2010;38:1584-1590.

31. Lee H-J, Jeong J-Y, Kim C-K, Kim Y-S. Surgical treatment of lesions of the long head of the biceps brachii tendon with rotator cuff tear: A prospective randomized clinical trial comparing the clinical results of tenotomy and tenodesis. J Shoulder Elbow Surg 2016;25:1107-1114.

32. Mardani-Kivi M, Mobarakeh MK, Keyhani S, Ebrahimzadeh MS, Ghadim-Limudahi ZH. Treatment of long head of biceps tendon lesions together with rotator cuff tears: Which method is preferred? Tenotomy or tenodesis. Tech Shoulder Elbow Surg 2018;19:101-105.

33. Meraner D, Sternberg C, Vega J, Hahne J, Kleine M, Leuzinger J. Arthroscopic tenodesis versus tenotomy of the long head of biceps tendon in simultaneous rotator cuff repair. Arch Orthop Trauma Surg 2016;136:101-106.

34. Oh JH, Lee YH, Kim SH, et al. Comparison of treatments for superior labrum-biceps complex lesions with concomitant rotator cuff repair: A prospective, randomized, comparative analysis of debridement, biceps tenotomy, and biceps tenodesis. Arthroscopy 2016;32:958-967.

35. Şentürk I, Özalay M, Akpinar S, Leblebici B, Murat çinar B, Tuncay C. Clinical and isokinetic comparison between tenotomy and tenodesis in biceps pathologies. Acta Orthop Traumatol Turc 2011;45:41-46.

36. Shank JR, Singleton SB, Braun S, et al. A comparison of forearm supination and elbow flexion strength in patients with long head of the biceps tenotomy or tenodesis. Arthroscopy 2011;27:9-16.

37. Wittstein JR, Queen R, Abbey A, Toth A, Moorman CT 3rd. Isokinetic strength, endurance, and subjective outcomes after biceps tenotomy versus tenodesis: A postoperative study. Am J Sports Med 2011;39: 857-865. 
38. Zhang Q, Zhou J, Ge H, Cheng B. Tenotomy or tenodesis for long head biceps lesions in shoulders with reparable rotator cuff tears: A prospective randomised trial. Knee Surg Sport Traumatol Arthrosc 2015;23:464-469.

39. van Deurzen DFP, Scholtes VAB, Willigenburg NW, et al. Long head BIceps TEnodesis or tenotomy in arthroscopic rotator cuff repair: BITE study protocol. BMC Musculoskelet Disord 2016;17:375.

40. MacDonald P, Verhulst F, McRae S, et al. Biceps tenodesis versus tenotomy in the treatment of lesions of the long head of the biceps tendon in patients undergoing arthroscopic shoulder surgery: A prospective doubleblinded randomized controlled trial. Am J Sports Med 2020;48:1439-1449.

41. Aflatooni JO, Meek BD, Froehle AW, Bonner KF. Biceps tenotomy versus tenodesis: Patient-reported outcomes and satisfaction. J Orthop Surg Res 2020;15:56-66.

42. Shang X, Chen J, Chen S. A meta-analysis comparing tenotomy and tenodesis for treating rotator cuff tears combined with long head of the biceps tendon lesions. PLoS One 2017;12:e0185788.

43. Na Y, Zhu Y, Shi Y, et al. A meta-analysis comparing tenotomy or tenodesis for lesions of the long head of the biceps tendon with concomitant reparable rotator cuff tears. J Orthop Surg Res 2019;14:370.

44. Hong CK, Chang CH, Hsu KL, Kuan FC, Wang PH, Su WR. Patients older than 55 years prefer biceps tenodesis over tenotomy to the same degree as young patients. J Orthop Sci 2019. doi:10.1016/j.jos.2019.05.007. In press.

45. Zabrzyński J, Ł Paczesny, Łapaj Ł, Zabrzyńska A, Szwedowski D. The surgical treatment of the long head of biceps tendon and the autotenodesis phenomenon: An ultrasound and arthroscopic study. Folia Morphol (Warsz) 2020;79:395-401.
46. van Deurzen DFP, Garssen FL, Wessel RN, Kerkhoffs GMMJ, van den Bekerom MPJ, van Wier MF. The Popeye sign: A doctor's and not a patient's problem. J Shoulder Elbow Surg 2020:S1058-S2746. doi:10.1016/j. jse.2020.10.040. Online ahead of print.

47. Anil U, Hurley ET, Kingery MT, Pauzenberger L, Mullett H, Strauss EJ. Surgical treatment for long head of the biceps tendinopathy: A network meta-analysis. J Shoulder Elb Surg 2020;29:1289-1295.

48. van Deurzen DFP, Gurnani N, Alta TDW, Willems JH, Onstenk R, van den Bekerom MPJ. Suprapectoral versus subpectoral tenodesis for long head biceps brachii tendinopathy: A systematic review and meta-analysis. Orthop Traumatol Surg Res 2020;106:693-700.

49. Puzzitiello RN, Gowd AK, Liu JN, Agarwalla A, Verma NN, Forsythe B. Establishing minimal clinically important difference, substantial clinical benefit, and patient acceptable symptomatic state after biceps tenodesis. J Shoulder Elb Surg 2019;28:639-647.

50. Cvetanovich GL, Gowd AK, Liu JN, Nwachukwu BU, et al. Establishing clinically significant outcome after arthroscopic rotator cuff repair. J Shoulder Elbow Surg 2019;28:939-948.

51. Najafov E, Özal S, Kaptan AY, et al. Validity and reliability of the turkish version of LHB score. J Sport Rehabil 2020;30:30-36.

52. Sanders B, Lavery KP, Pennington S, Warner JJP. Clinical success of biceps tenodesis with and without release of the transverse humeral ligament. I Shoulder Elbow Surg 2012;21:66-71.

53. van Deurzen DFP, Garssen FL, Kerkhoffs GMMJ, Bleys RLAW, Ten Have I, van den Bekerom MPJ. Clinical relevance of the anatomy of the long head bicipital groove, an evidence-based review. Clin Anat 2020. doi:10. 1002/ca.23610. In press. 